\title{
LUSITANIA (1920): UN LIBRO OLVIDADO DE ROGELIO BUENDÍA EN LA ENCRUCIJADA ULTRAÍSTA
}

\author{
Juan Montero \\ Universidad de Córdoba
}

Hablar de un libro olvidado de Rogelio Buendía sonará a redundancia, pues todos los suyos — cual más, cual menos- lo están. Valga el título, sin embargo, por aquello de que la desmemoria se compadece mal con la crítica y la historia literaria.

No puede decirse, con todo, que la obra de Rogelio Buendía (Huelva, 1891-Madrid, 1969) haya sido completamente ignorada por la crítica. El profesor Martín A. Díez Urueña le ha dedicado recientemente una sucinta y útil monografía ${ }^{1}$. Por otra parte, el nombre del escritor aflora con alguna frecuencia en obras que se ocupan de las literaturas de vanguardia o de la generación del 27. Guillermo de Torre, por ejemplo, lo menciona — «un poeta y médico de Huelva»- entre los más asiduos colaboradores de Grecia ${ }^{2}$. Sobre todo, se le recuerda en su calidad de co-fundador y co-director, junto a Adriano del Valle y Fernando Villalón, de la revista Papel de Aleluyas, la escisión onubense de la sevillana Mediodía ${ }^{3}$. Danièle Musacchio ha resumido el itinerario de Buendía como colaborador de las revistas de vanguardia:

1 Martín A. Díez Urueña: Vida y obra de Rogelio Buendía. Córdoba, 1978. Además del estudio bio-bibliográfico y literario, comprende una antología poética (págs. 87-112), una relación de las publicaciones del escritor (págs. 115-116) y algunos documentos relativos al mismo (págs. 123-130). Por lo que hace a Lusitania, Díez Urueña ofrece dos indicaciones bibliográficas diferentes (pág. 40 y pág. 115), ninguna de las cuales coincide con la que presenta el ejemplar que hemos manejado; parece probable, por tanto, que no llegara a ver el libro.

2 G. de Torre: Historia de las literaturas de vanguardia. Madrid, Guadarrama, 1971, t. II, pág. 219. G. Videla le dedica una breve reseña bio-bibliográfica (vid. El ultraísmo. Estudios sobre movimientos poéticos de vanguardia en España. Madrid, Gredos, 1971, pág. 164, y también el índice de nombres).

3 J. Issorel (ed.): Papel de Aleluyas. Revista andaluza del 27. Huelva, Diputación Provincial, 1980. En la pág. 15 del estudio introductorio se indica que Buendía abandonó el Comité Directivo de la revista a partir del núm. 5 (marzo de 1928), cuando la misma pasó a publicarse en Sevilla. 
«Su nombre se asocia al de numerosas revistas ultraístas de la época, ya porque colaborara en ellas, ya porque - la mayoría de las veces- participara en su dirección. Fue, en 1916, colaborador de Los Quijotes y de Cervantes, en 1919 formó parte del comité de dirección de Grecia, en 1922 colaboró en Tableros, en 1922-23 en Horizonte y a partir de 1923 en Alfar. Por último, respecto al periodo que nos atañe, fundó en 1927, junto con dos sevillanos (F. Villalón y A. del Valle) la revista Papel de Aleluyas, en su ciudad natal de Huelva. Colaboró una vez en Mediodía en septiembre de 1926, en el número 3, donde reunió siete poemas bajo el título de «Poemas de la vida en el Puerto» ${ }^{4}$.

Su producción poética no escasea en títulos. Los primeros suenan a romanticismo juvenil y modernismo: El poema de mis sueños (Madrid, 1912), Del bien y del mal (Madrid, 1913), Nácares (Sevilla, 1916); los que les siguen son ultraístas: La rueda de color (Huelva, 1923), Guía de jardines (Sevilla, 1928) y Naufragio en tres cuerdas de guitarra (Sevilla, 1930). En el campo de la prosa, Buendía es autor, señaladamente, de un par de novelas cortas ${ }^{5}$ y de la obra que aquí nos ocupa, Lusitania, un libro de impresiones de viaje.

Lusitania. Viaje por un país romántico (1918) fue publicado por la editorial madrileña Reus en 1920. Lo integran una serie de notas de viaje cuya peculiaridad literaria reside en el hecho de haber sido redactadas a modo de poemas en prosa. Desde el punto de vista temático e ideológico, lo más llamativo de la obra es su marcado iberismo, presente desde la misma dedicatoria: «A los buenos patriotas que en Portugal y en España sienten el hermoso ideal del iberismo».

El libro se halla dividido en diversas secciones: «El viaje», «Oración en medio de la noche», «Lisboa», «Cintra», «Cascaes», «Coimbra», «En el tren», «Otra vez en España»; hay además unos «Recuerdos que pueden servir de prólogo» (referidos a un tiempo anterior al del viaje) y un epílogo desde París («1918-1920»). La mayoría de las secciones constan de un solo texto, salvo «El viaje» (tres), «Lisboa» (nueve) y «Coimbra» (ocho). Las diversas secciones diseñan un orden cronoespacial fácilmente perceptible. Ahora bien, los 27 textos que componen el libro se inscriben dentro de ese marco unitario como breves fragmentos discontinuos, de manera que la estructura viene a resultar más impresionista o lírica que narrativa o ensayística.

De lo dicho se deduce que Lusitania es, ante todo, un libro de prosa poética. Su encuadre dentro del panorama trazado por G. Díaz-Plaja en su conocido estu-

4 D. Musacchio: La Revista Mediodía de Sevilla. Universidad de Sevilla, 1980, pág. 147. Es inexacto que Buendía colaborase en Cervantes el año de 1916; en realidad empezó a hacerlo en 1919 (vid. L. Bianchi: «Cronaca e storia di una rivista spagnola d'avanguardia: Cervantes», Studi di Letteratura Spagnola. Roma, 1968-1970, págs. 279-329). Pudiera ser errónea, asimismo, la indicación acerca de Los Quijotes, aunque también la da G. Videla (op. cit., pág. 42). Díez Urueña cita, por su parte, una colaboración en Meseta, núm. 2 (Valladolid, 1928). José Ma Barrera López acaba de rescatar en un espléndido trabajo las colaboraciones de Buendía en Grecia, Gran Guiñol y El Liberal de Sevilla entre 1918 y 1921; vid. ahora El ultraísmo en Sevilla. Sevilla, Alfar, 1987, t. I, págs. 92-117.

5 La casa en ruinas. Madrid, 1913 (Colección «La novela de bolsillo», núm. 99). Y La dorada mediocridad. Sevilla, 1923 (Colección «La novela del día», núm. 7). Esta última va dedicada a un cofrade ultraísta: «A José María Romero, que en mis divinos años de Sevilla, caminó junto a mí por los caminos claros de Apolo y por los inextricables bosques de Asklepios». En una nota preliminar adjunta al relato se llama a Buendía «el poeta de los siete viajes fabulosos». 
dio sobre el tema, nos llevaría a catalogar a Buendía entre los llamados cronistas líricos ${ }^{6}$. La prosa de Buendía dista, sin embargo, de alcanzar el nivel de la de otros cultivadores del género. Situado en una estela romántico-modernista, el onubense sólo conserva de sus maestros (Bécquer, Darío, Juan Ramón) el hálito emotivo y sensorial, convertido las más de las veces en fórmula o pose. Carece de capacidad descriptiva, de intensidad dramática o lírica: carece, sobre todo, de naturalidad - baste un dato: todo el libro está redactado en plural de modestia. Por eso, sus buenos momentos, que los tiene, no pasan de ser estampas con regusto a modernismo aprendido y algo amanerado.

\section{Los registros del viajero.}

Como era de esperar, en Lusitania se dan cita las diversas modalidades de la literatura de viajes, configuradas por una tradición que tuvo en la generación de fin de siglo uno de sus momentos álgidos:

«Esa herencia [de la Institución Libre de Enseñanza] y el interés de los modernistas por la observación de lo natural y por los viajes conformaron la preocupación por el paisaje español de la generación de fin de siglo: en unos predominará la impresión moral y regeneracionista; en otros, la captación del detalle y la muy modernista sensación de lo efímero de la condición de viajero; en aquéllos, la impresión personal de paz o desasosiego, pero, fuera como fuera, el paisaje de España cobró casi condición de protagonista literario (como Azorín pudo aseverar en la famosa obra publicada en 1917). Hubo incluso una nada desdeñable literatura de viajes que incluye títulos de Unamuno, Azorín y Baroja, además de otros que no merecen el olvido de hoy...» ${ }^{7}$.

Si la asociación con Unamuno resulta en este caso inevitable, lo cierto es que no hay en Lusitania huellas apreciables de Por tierras de Portugal y España. Independientemente de esto, la verdad es que nuestro viajero se interesa menos, en líneas generales, por el paisaje que por lo urbano. Es más, la descripción paisajística resulta sistemáticamente eludida y hasta escamoteada. Buscamos en el índice: «Ayamonte», y apenas encontramos unas líneas acerca de sus crepúsculos, «Algarve», menos todavía; «La luna en el mar», otro tanto; «La fuente dos paxarinhos»:

«Nada tan grandioso como este panorama que se divisa desde el castillo de Cintra. Frente a estos distintos tonos verdes, azules, amarillos y rojos parece que estamos subidos sobre un monte en el que hubieran echado negligentemente un maravilloso tapiz persa.

¿Qué decir de un paisaje tan universal, del que tantas bellas cosas se han dicho? No intentemos decir nada.»

6 G. Díaz-Plaja: El poema en prosa en España. Estudio crítico y antología. Barcelona, Gustavo Gili, 1956.

7 J. C. Mainer: La edad de plata. Madrid, Cátedra, 1981, pág. 126. 
La naturaleza urbanizada y doméstica no deja de atraer, sin embargo, al viajero. Lisboa, por ejemplo, es el Tajo, el Jardín Botánico y Zoológico, los árboles y cúpulas dorados por el sol:

«Ninguna ciudad del mundo podrá tener otra entrada más triunfal.

¡Lisboa! El oro del sol de la mañana dora las cúpulas de las iglesias y los tejados de las casas.

Las palmeras rampan por encima de las calles como jardines colgantes gigantescos». («En la ciudad»).

Tanto en la ciudad como en los intervalos rurales, el viajero se entrega a la descripción, al natural, de tipos y ambientes con sabor local. Desfilan así por el libro pescadores ayamontinos y algarabíos, soldados en desplazamiento, mujeres veraneantes, pescaderas lisboetas, personajes anónimos de los parques y cafés, transeúntes. En la mayoría de los casos se trata de brevísimos apuntes que procuran atisbar el alma lusitana:

«Faro, Portimao, Loulé... Pueblos de donde vienen estos buenos hombres, francos y habladores, que entran en el tren con su paraguas y sus sombreros de anchas alas.

¿Adónde van estos hombres extraños con el paraguas cerrado siempre y los abrigos largos, interminables, de colores indefinidos, con cinco y seis hileras de esclavinas?

¿Cómo pueden soportar este calor de trópico bajo esas amplias mantas escaroladas?» («Algarve»).

«Al entrar en Lisboa nos ha llamado la atención ver que todo el mundo lleva un maletín en la mano, y que algunas personas van agobiadas por el peso de verdaderas maletas.

Esto da la impresión de un pueblo que está siempre viajando, y alguna vez nos parecen estos hombres y estas mujeres tremendos anarquistas, que llevan en el fondo de sus maletines explosivos para sus atentados». («Las campanas del Botánico»).

«Seguimos nuestro solitario deambular.

Oímos pregones tristes como los de Castilla.

Unas mujeres llevan cargas de frutas de vivos colores.

Van de dos en dos y llevan grandes canastos por las asas.

Estas mujeres visten como las pescaderas de Lisboa; pero llevan un sombrerito inverosímil de terciopelo negro, parecido al sombrero andaluz llamado de queso. Las alas del sombrero, curvadas para arriba, las llevan cubiertas de cintas, plumas y flores». («El alma de Portugal»).

Otras veces, las menos, la observación se hace más demorada, buscando la caracterización física y anímica de algún personaje individualizado. Así ocurre en «Un hidalgo pobre», retrato de un curioso cliente de un restaurante lisboeta, o en «La negra sueña en su balcón», uno de los momentos más logrados del libro:

«Al pasar por una acera de la avenida de la Libertad, esta gran avenida tan europea, hemos sorprendido la tragedia de la saudade africana. Una negra joven, de facciones regulares y pelo ensortijado, vestida de rosa y con unos grandes pendientes de aro en las orejas, deja vagar su mirada sobre los castaños de Indias de los paseos laterales. 
Los ojos de la negra, de un blanco y un negro casi luminosos, miran de pronto con un ansia de imposible, hacia un sitio elevado. Es una palmera que emerge por entre los tejados de una casa.

¿Del Congo, de Lorenzo Márquez, de Mozambique, de Guinea? De una de estas tierras de sol has venido. $\mathrm{Y}$ aun ante esta flora tan exuberante, tus ojos de cristal buscan árboles más altos y tus narices de aletas dilatadas, perfumes más violentos.

La mano en la mejilla, con su traje rosa y sus grandes aros de oro, la negra llora frente a la palmera del recuerdo» ${ }^{8}$.

La indagación de los ambientes urbanos lleva al viajero a convertirse en cronista de la actualidad cultural o festiva. Una corrida de toros (con sus correspondientes forcados), la cartelera teatral, los estantes de una librería son otras tantas ocasiones para tomarle el pulso a la nación. La historia se filtra en el libro a través de las inevitables visitas monumentales, en las que nuestro viajero adopta aires de connaisseur, sin abandonar por ello su habitual perspectiva poética:

«...hemos entrado en los Jerónimos y hemos sentido una palpitación de vida.

Unos niños vestidos de azul juegan entre las hermosas columnas finamente labradas.

El claustro parece que se humaniza, que por la nervadura de sus bóvedas, recogidas en haces sobre los capiteles, corre sangre viva, la sangre joven de los niños que nunca supieron de sus padres.

Estos niños azules de los Jerónimos, que juegan entre las columnas del claustro, son las golondrinas de la torre de un hermoso castillo abandonado». («Las golondrinas azules»).

Este capítulo erudito incluye también el consabido encuentro con una figura de las letras. En este caso le toca a Eugenio de Castro - «el poeta más lírico de todos los actuales líricos lusitanos»- cumplir en Coimbra con ese papel de anfitrión y guía.

\section{La perspectiva ideológica.}

Que nuestro viajero haga gala de conocimientos histórico-artísticos y amistades literarias no le impide adoptar, llegado el caso, una actitud que tiene mucho de popularista. «Mujeres de Lisboa» es un texto significativo al respecto. En tanto que las veraneantes de Estoril o Cascaes representan a sus ojos una especie de frivolidad internacional, las pescaderas de Lisboa le impresionan hondamente:

«Son las pescaderas de Lisboa, de amplias faldas pintorescamente coloreadas, de corpiño de terciopelo y de minúsculos sombreritos redondos, sobre los que sostienen la plata del pescado fresco, recién salido de las barcas. Son estas las mujeres que nos encantaron. Tienen todas el pelo negro y brillante, cubrien-

8 Son notables las similitudes (y diferencias) de la estampa con la imagen parisina, de Baudelaire: «Je pense à la négresse, amaigrie et phtisique, / Piétinant dans la boue, et cherchant, l'ogeil égard, / Les cocotiers absents de la superbe Afrique / Derrière la muraille immense du brouillard.» («Le Cygne», vv. 41-44; Les fleurs du mal et autres poémes. París, Garnier-Flammarion, 1964, pág. 108). 
do las orejas, de cuyos lóbulos penden grandes zarcillos de oro bien trabajado. Todas tienen ojos negros, las narices de nobles proporciones, las bocas como jugosos higos frescos.

Esta mujeres morenas, serias y de lento andar, que llevan sobre sus cabezas el peso de su pescado de plata, son las que llenaron nuestro vaso espiritual, ávido siempre de símbolos».

Lo curioso del caso es que el popularismo del escritor esta claramente moldeado sobre la visión que tiene de su propia tierra, Andalucía ${ }^{9}$ :

«Maravillados estamos de ti que eres femenina y grácil como el Argarve es serio y hombruno.

Lejos de ti oímos todos tus campaniles gloriosos, escuchamos tus voces de ensueño sonrosado.

Una mano detrás de un visillo, una copla detrás de una esquina, y la luz cegándolo todo con anchas planchas de oro.

Te sentimos ahora correr por nuestras venas y te atraviesan aquí, en lo hondo del corazón, llenándonos de ternura.

Nuestra mano busca inútilmente la mano que alzaba el visillo.

¡Andalucía!» («Elogio de Andalucía»).

La transposición de la andaluz a lo lusitano se realiza sin rebozo alguno. Durante el recorrido en tren por el Algarve el viajero escribe con letra indecisa unos versos sencillos en los que se superponen el fado y la copla:

«En el ambiente fluctúa el triste aroma de un fado que se hubiese eternizado en la quietud de la rúa.

Sol cayendo a plomo... Una guitarra llora, en la reja en flor, la cantiga vieja de resignación moruna.

En una ventana abierta sueñan unos ojos.

\section{Cruza}

por la plazuela desierta una mujer. Me ha mirado, y en su mirada andaluza he visto llorar un fado».

$$
\text { («Algarve») }
$$

De la misma manera, al llegar a Coimbra el viajero se siente estar en Sevilla:

$9 \mathrm{El}$ andalucismo de Buendía no es, naturalmente, un hecho aislado. Baste recordar la presencia de este ideario en revistas como Bética (en la que Buendía incluyó tres colaboraciones) y su entorno; vid. J. Cortines Torres: Índice bibliográfico de «Bética, Revista ilustrada». (Sevilla, 1913-1917). Sevilla, Diputación Provincial, 1971, con abundante documentación y análisis en págs. 23-56 de la Introducción. 
«iEstas son las calles y las plazas de Sevilla!

En las azoteas y en los balcones, macetas con enredaderas que enguirnaldan las callejuelas de fachada a fachada, dando un verde brillante sobre el azul intensísimo del cielo. Hasta las caras, que se asoman tímidamente por entre las celosías, son como las de las mujeres sevillanas: graciosas y morenas.» («Las calles de Sevilla»).

Este reencuentro con una imagen de la propia región quizá nos dé la clave del fervoroso iberismo que profesa Buendía. Se trata de un sentimiento, una ilusión, más que de un ideario político:

«En una orilla está Ayamonte: España; en la otra, Villarreal de Santo Antonio: Portugal...

Y la imaginación forja ideas de hermandad, ideas de comunión de ideales.

A pesar de que la política y la Historia tienden a separarnos, nosotros sentimos simpatías por ese pueblo hermano que habla un castellano más dulce, y lleva su melancolía con más gallardía que nosotros nuestra rebelde tristeza». («Ayamonte»).

Son ganas de soñar despierto:

«Los que en la parte hispánica de la Península pensamos en el iberismo, somos unos soñadores que quisiéramos que ambos pueblos se compenetrasen de manera tan consustancial, que viniese de ello el convencimiento de una necesaria unión federativa.

Y hasta soñamos con la capitalidad de esta gran confederación. Lisboa, por su situación atlántica, por su preciosa posición topográfica, por su belleza única, sería la capital de Iberia, de una Iberia grande, inexpugnable, adonde todo el genio peninsular brillaría como un faro que irradiase una luz inextinguible». («Teatros. Iberismo»).

Este sentimiento iberista sólo adquiere algún tinte de reflexión al final del libro, tras el retorno del viajero a tierras españolas. Entonces puede comprobarse que el iberismo surge en Buendía como expresión de una actitud crítica para con la realidad española: una actitud regeneracionista, en definitiva. El escritor se indigna con los españoles que miran por encima del hombro a los portugueses:

«iQué desconocimiento más completo de lo que es el país lusitano demuestran al pensar así, con ese desprecio orgulloso, de una tierra que es toda ella un jardín floreciente y donde la raza ibera bulle con más calor y late con más pulso que en esta tierra española!». («Divagaciones»).

La vitalidad portuguesa se refleja, a juicio del viajero, tanto en el orden material como en lo espiritual:

«En todas partes hemos notado una gran actividad progresiva.

$\mathrm{Y}$ junto a todo esto, un gran romanticismo, ese exaltado romanticismo que hace poetas a sus hombres de ciencia y a sus guerreros. Ese romanticismo es el que nos falta a los españoles, quienes estamos carentes de ideales concretos». («Divagaciones») 
Si los españoles despertasen de su letargo, viene a concluir Buendía, el ideal ibérico serviría de acicate y cauce para el reencuentro con las grandezas de la raza:

«Pensábamos en un futuro en que, las dos naciones ibéricas unidas, irían a la magna empresa de hacer amar en América las tradiciones de la raza, el arte ibérico, la cultura de Iberia.

España, Portugal, América española, Brasil... Ese sería el periplo de nuestro sueño.

Grandes barcos llevarían de nuestros puertos para los de América un enorme bagaje de libros, de hombres, de manufacturas, y de allí vendrían a nosotros los emocionados espíritus de los hijos de nuestro esfuerzo racial». («Divagaciones»).

Parece claro que este planteamiento iberista no resiste una crítica seria. La eventual unificación o confederación política de España y Portugal era, como el mismo Buendía no podía ignorar, algo que los propios iberistas lusos de la época descartaban de plano, una reliquia de los inicios decimonónicos del movimiento ${ }^{10}$. De la misma manera, tampoco encontramos afirmaciones semejantes en Unamuno, por citar al más conspicuo iberista español ${ }^{11}$. El iberismo de Buendía, expansión de su regionalismo popularista, sólo tiene algún sentido histórico en tanto que núcleo de una retórica casticista y regeneracionista de la hispanidad, difundida a raíz de la crisis de fin de siglo y llamada a integrarse en la cultura oficial de la España alfonsina (1917: institución de la Fiesta de la Raza; 1929: Exposición Iberoamericana de Sevilla). No conviene, sin embargo, desatender el impacto que tales ideas tuvieron sobre algunas de las publicaciones de la vanguardia española, como es el caso de Cervantes, que apareció en 1916 con el subtítulo de Revista Mensual Ibero-Americana, transformado desde 1917 en el de Revista Hispanoamericana ${ }^{12}$. Más concretamente los primeros números de esta revista incluyen con mucha frecuencia trabajos relacionados con Portugal: colaboraciones de E. de Castro, Guerra Junqueiro, A. Nobre; reseñas sobre actualidad literaria del país vecino; apuntes de algún viajero (F. Trigo: «Recuerdos de Portugal», núm. 2 sept. 1916, pág. 15), etc. ${ }^{13}$.

10 Estos extremos los ducumenta bien J. García Morejón: Unamuno y Portugal. Madrid, Gredos, 1971, págs. 335 y ss. La tendencia lírica de su iberismo llevó a Buendía a redactar una «Canción de España y Portugal», publicada en Huelva. Revista de Turismo, 1922.

11 «La fórmula unamuniana del iberismo (...) es ésta: englobar espiritualmente a todos los pueblos peninsulares, y a los ultramarinos también, en los que la acción de Portugal y España se haya dejado sentir». (J. García Morejón, op. cit., pág. 352). Con más idealismo y pasión se manifestó sobre el tema (especialmente en su correspondencia con Unamuno) Joan Maragall, «uno de los más exaltados iberistas de todos los tiempos, si no el más exaltado iberista español» (op. cit., págs. 357 y ss.).

12 Esta filiación la ha subrayado J. C. Mainer: «... su definición como «Revista Hispanoamericana» la convierte en heredera directa de aquella vaga internacional literaria que el prestigio transoceánico de Rubén Darío, los sentimentalismos que sucedieron al Desastre y los intereses mercantiles de los editores de principios de siglo alentaron a ambas orillas del Atlántico...» (op. cit., pág. 209). También ha tocado el tema V. García de la Concha: «Dos revistas cervantinas en las primeras escaramuzas de la vanguardia», en Homenaje a Torrente Ballester. Salamanca, Biblioteca de la Caja de Ahorros y Monte de Piedad, 1981, págs. 409-423.

13 Repasando los índices de Cervantes se comprueba que las colaboraciones de tema o autor lusitanos se concentran de forma especial en los cinco números de 1916, al par que se hacen raras desde mediados de 1917 (vid. L. Bianchi, art. cit., págs. 308 y ss.). 
En conclusión, cabe trazar una trayectoria posible del iberismo de Buendía como un sentimiento que enraizado en sus propias circunstancias personales (familia originaria de Ayamonte, una abuela paterna de nacionalidad portuguesa...), se afianza y eleva a categoría de ideal en el contacto con el ibero-americanismo del ambiente cultural y literario, del que pudo tener experiencia directa en revistas como las ya citadas Bética (que le dejó al paso la marca de su andalucismo) y Cervantes.

\section{La encrucijada estética.}

Tras su fachada regeneracionista, el iberismo de Buendía tiene una impronta marcadamente romántica, tanto en lo que se refiere al planteamiento históricopolítico, como a la misma valoración de la cultura lusitana. En realidad, el supuesto romanticismo del alma portuguesa no es más que el espejo sobre el que Buendía proyecta la imagen del romántico que lleva dentro, una imagen en la que se combinan, atenuándose mutuamente, la rebeldía de Espronceda y el intimismo de Bécquer — dos autores recordados en Lusitania. El modernismo impresionista y sentimental que caracteriza estilísticamente el libro, es el idioma en que se expresa ese romántico que anima por dentro al autor:

«¡Diez y siete horas en tren bajo un sol de fuego durante el día y un cielo negro y oro en la noche, sin un soplo de brisa para nuestra frente perlada de sudor!

¡Por fin llegamos a Barreiro! Es por la mañana. Un vapor nos lleva a Lisboa, cruzando al Tajo, que no tiene la menor ondulación. ¡Oh, maravilla de las maravillas!

Ninguna ciudad del mundo podrá tener otra entrada más triunfal». («En la ciudad»).

Así las cosas, resulta inevitable pensar que la inminente conversión de Buendía al ultraísmo debe valorarse, ante todo, como un nuevo avatar de ese romántico interior. Cabe plantearse, asimismo, si Lusitania deja traslucir algún síntoma de dicha transformación, La respuesta es que algo de ello hay, en efecto. El primer signo es, como no podía ser menos, de índole culturalista. Antes de iniciar su periplo, el viajero pasa por una finca próxima a Ayamonte, con idea de saludar a un amigo que responde al poético nombre de Cardenio ${ }^{14}$. La visita lo soprende leyendo un libro... de Ramón Gómez de la Serna, Muestrario.

Aparte de esto, es verdad que a veces afloran en Lusitania atisbos de un estilo nuevo. El «Elogio de Andalucía» concluye, por ejemplo, con una frase que tiene mucho —no todo- de una greguería:

«La luna es una naranja del aquel jardín de las Hespérides».

Alguna que otra imagen apunta hacia la modernidad:

14 La identificación exacta de este personaje es arriesgada. Dado el origen ayamontino de la familia, pudiera tratarse de alguien allegado al poeta, quizá su propio padre, Rogelio Buendía Abréu, librero y novelista (vid. M. A. Díez Urueña, op. cit., págs. 13-15). 
«El sol dora las cúpulas, y hay en cada cristal un pedazo de sol pegado como una lámina de papel de estaño». («En la ciudad»).

«Batalla en el Acuarium», que es sin duda el texto más singular del libro, tiene algo del léxico, la iconoclastia, el humorismo pueril de la vanguardia:

«Nos ha interesado más que la estatua de Eça de Queiroz que hay en una plaza de la calle d'Alecrim y donde la falsa verdad de un mal escultor está cubriéndose con el menguado velo de una pobre fantasía ${ }^{15}$, nos ha interesado más que el panteón de los reyes, y, sobre todo, nos ha regocijado mucho, las peleas de los monos en el jardín Zoológico y la batalla en el Acuarium.

Un amigo sevillano que nos acompañaba, Villagrán, sacó de una piscina un choco - no sabemos el nombre técnico de este cefalópodo-y lo trasladó a otra, adonde había innúmeros pececillos. Cuando vieron éstos al intruso le atacaron encarnizadamente a las patas de su locomotiva cabeza.

El pobre choco soltaba descargas de su pólvora negra para desconcertar al enemigo. El agua se enturbiaba; pero, al momento, volvían los peces al ataque.

Hubo un instante en que el cefalópodo quedó desangrado y flotó, inerme, perdida la esperanza, en la superficie del líquido. Entonces nosotros, compadecidos, cogimos al cansado animal y lo restituimos al reino de sus aguas... y fue feliz».

Los juegos del acuario no son, sin embargo, sino bromas ocasionales de muchachos bienhumorados. La pose habitual del viajero es muy otra. Un transeúnte observado en Lisboa se le ha grabado en el recuerdo:

«Nuestro hombre llevaba un chaqué anticuado, barba recortada como nuestro Bécquer, y, también como Gustavo Adolfo, una revuelta melena que se desrizaba fuera de las alas abarquilladas de su prestancioso hongo.

Será siempre este portugués romántico, esculpa, versifique, o simplemente no haga nada, por su cabeza interesante de ojos oscuros y labios finos, y porque seguramente se escapó del año treinta para andar torpemente por entre los automóviles y los tranvías, quien represente a Portugal en el fondo de nuestros recuerdos simbólicos». («Divagaciones»).

En el texto que cierra la obra, fechado en 1920, vemos al mismo escritor que en otra parte del libro clamaba por el progreso material de la nación, aturdirse ante el espectáculo de una gran ciudad moderna ${ }^{16}$ :

«Aquí en París, no podríamos experimentar las dulces sensaciones que fueron escritas en Portugal. Sentimos que los pensamientos se densifican y que to-

15 Unamuno habla, en cambio, del «hermoso monumento a Eça de Queiroz»: «La grave inspiración de Teixeira Lopes ha logrado dar una muy íntima expresión al rostro del terrible psicólogo, del hombre implacable para las flaquezas de su tierra.

Aquel hastiado, aquel escéptico, se inclina para mirar con mirada escudriñadora la imagen de la Verdad, sobre cuya 'fuerte desnudez' quiso echar 'el manto diáfano de la fantasía'. (Esta su frase figura al pie del monumento.)» (Por tierras de Portugal y de España. Andanzas y visiones españolas. Madrid, Aguilar, 1953, pág. 132).

16 M. A. Díez Urueña precisa las circunstancias del viaje en cuestión: «En 1920 hizo un viaje a París, en cuya Universidad siguió un curso sobre enfermedades del pecho, organizado en la Facultad de Medicina, en colaboración con la Fundación Rockefeller» (op. cit., pág. 32). 
do lo espirituoso y vagamente sutil que llenaba nuestro vaso, se condensa y se acidula. El grito del bulevar, el vermellón de los labios, el humo de los automóviles, los chirridos y las vibraciones de los cables, las arterias latentes del metropolitano, los saltos de piedra de las calles de una a otra orilla del Sena, van entumeciendo la sutilidad y la van complicando». («1918-1920»).

El viajero rememora entonces unos versos de Moréas ( «J'aime ton jeune éclat et tes beautés fanées») que cantan la luna de París ${ }^{17}$, mientras se retira en busca de escenarios más apacibles, que encuentra al fin:

«Fue en la calle de Saint Louis en l'Ile, una calle vieja y provinciana oculta entre los bulevares de alrededor de los muelles, una calle con letreros en rojo: CHARCUTERIE-PATISSERIE-TRIPERIE-CHARBONS-PASSEMENTERIEBOUILLON... Tiendecitas con cortinas de cretona rameada, con gentes de buenas caras redondas sentadas en las puertas...

Una charanga del quartier tocaba un vals respingón rodeada de chiquillos.

El sol iluminaba oblicuamente un edificio viejo: la Escuela Municipal. Dos novios — como en provincias— hablaban de balcón a balcón...» («1918-1920»).

Que la tensión entre metrópoli y provincia se decante en Lusitania a favor de la segunda resulta sin duda sintomático. Por este y otros motivos ya indicados (estilísticos e ideológicos) el libro se convierte en un testimonio menor, pero interesante, del componente romántico-modernista detectable en los orígenes mismos del Ultra: un lastre - valga la palabra - del que, como es sabido, pocos militantes del movimiento V. P. lograron liberarse plenamente ${ }^{18}$.

17 La cita de Moréas tiene un indudable interés culturalista. Como también lo tiene la omisión de cualquier referencia a capítulos destacados de la vanguardia portuguesa (vgr. la aparición en 1915 de Orpheu). En La dorada mediocridad (pág. 20), por el contrario, el ambiente parisino se asocia con los «Poemas de París» de Sá-Carneiro: «O meu Paris, meu menino, (...). ¡Dichoso Mario SáCarneiro! Se supo matar a tiempo. El [Marcos], en cambio, estaba de pie, porque el muerto está en pie». Al fondo, como siempre, Bécquer.

18 De ello da testimonio, inmediato e irónico a la vez, R. Cansinos-Assens en la novela de ese título (El movimiento V. P. Ed. de J. M. Bonet, Pamplona, Hiperión, 1978). 
